\title{
Research on the Illogical Phenomena Existing in English Language
}

\author{
Chi Zhang \\ Foreign Language Department, Hubei University of Automotive Technology, Shiyan, Hubei, China \\ zhangc58@126.com
}

\begin{abstract}
Beginning with the relationship between human languages and human thoughts, this paper expounds firstly on the logicality of human thoughts and human languages. Since human thoughts share common logic characteristics and, human languages reflect those thoughts, languages usually have some common logic characteristics as well. Then it elaborates upon the large variety of illogical phenomena existing in three aspects of the English language — the rules of pronunciation, the words' formation, and the syntactic meanings. At last, it analyzes the causes of these illogical phenomena and the enlightenments they bring to usalthough they increase the difficulty of English learning, they enrich the English language as well thus, making the English language more colorful and intriguing.
\end{abstract}

Index Terms - English; language; thought; illogical phenomena

\section{The Logicality of Human Thoughts and Languages}

\section{A. The Logicality of Human Thoughts}

As we all know, human thoughts are a function of the human brains, which is the long-term developmental products of the natural world. In human's practice process, people's sense organs "touch" the objects and form the perceptual knowledge of the objective world in the brain through nerve conduction. As people's practice goes on, out of the perceptual knowledge, the concepts, judgments and inferences come into being. These concepts, judgments and inferences eventually leap into rational knowledge-thoughts. Since human thoughts reflect the objective world independentlyunaffected by the human's wills, human thoughts are the same in logicality [1]. And, this is why people from different nations, with different languages and cultural backgrounds can communicate successfully.

\section{B. The Logicality of Human Languages}

Languages and thoughts are interdependent. While thoughts are the tools people use to cognize the objective world; languages are the tools people use to exchange their thoughts. In the course of human communication, thoughts are the communication contents while languages are the communication forms. Generally speaking, the content decides the form. Therefore, human languages inevitably manifest the accordance with the logicality of human thoughts.

The universality of human thoughts determines certain commonality of some languages. Take Chinese and English for example, although they are different in nature (Chinese is mainly a language signifying the meaning; while English is mainly a language signifying the pronunciation), they undeniably share some common ground - - they both have ten parts of speech; four classifications of sentences according to the sentence purposes; and subject, predicate, objective, etc. as sentence constituents. This means languages as well as thoughts have some logicality.

There is also a correspondence between languages and thoughts. This correspondence is believed to be the common law of human languages. So, all languages must obey certain rules or laws or, must accord with the logic of human thoughts to communicate effectively. Take English for another example, the spelling, the word formation and the sentence making, all have their rules or laws — rules of pronunciation, rules of word formation and rules of sentence making.

Nevertheless, the objective world is complicated. There is no rule that has no exception. Languages are the same. There are many language phenomena in English that does not accord with these rules or the logic of human thoughts. This paper discusses the illogical language phenomena existing in English language from three aspects: pronunciation and spelling, word form and word meaning, as well as syntax and syntactic meaning.

\section{Illogical Phenomena Existing in English Language}

\section{A. Illogical Phenomena Existing in English Pronunciation and Spelling}

English, as discussed above, is mainly a language signifying the pronunciation. That is to say that the English spelling has a close relationship with its pronunciation. This relationship is what we call pronunciation rules. However, in English spelling and pronunciation, there are a lot of cases which do not accord with pronunciation rules, i.e. illogical pronunciation phenomena.

For example, there are 26 letters in English alphabet; each of them has a fixed pronunciation in words according to some rules, although some of them may have different pronunciations in different cases. These rules are called pronunciation rules. But, there are so many exceptions or special cases in English pronunciation and spelling.

Firstly, the 26 letters can be mute letters in a few cases. See the following table: 
TABLE I Cases of 24 Mute Letters (Underlined Letters in Words)

\begin{tabular}{|c|c|c|c|c|c|}
\hline \multicolumn{6}{|c|}{ Cases of 24 Mute Letters (Underlined Letters in Words) } \\
\hline A & Encyclopaedia & I & Friend & Q & Lacquer \\
\hline B & Debt & $\mathrm{J}$ & Rijn & $\mathrm{R}$ & Iron \\
\hline $\mathrm{C}$ & Victual & K & $\underline{\text { Know }}$ & S & Island \\
\hline $\mathrm{D}$ & Handkerchief & $\mathrm{L}$ & Calm & $\mathrm{T}$ & Castle \\
\hline E & Give & M & Mnemonics & U & Guard \\
\hline $\mathrm{F}$ & Halfpenny & $\mathrm{N}$ & Autumn & $\mathrm{W}$ & Wrong \\
\hline G & $\underline{\text { Gnaw }}$ & $\mathrm{O}$ & People & $\mathrm{X}$ & Grand Prix \\
\hline $\mathrm{H}$ & Hour & $\mathrm{P}$ & Psychology & Y & Pepys \\
\hline
\end{tabular}

Secondly, English letters sometimes are not pronounced according to the rules, such as have, shone, give, live, to, do, who, move, ate, etc. All these words are open syllables but read [hæv], [S $ว \mathrm{n}$ ], [giv], [liv], [tu:], [du:], [hu:], [mu:v] and [et] respectively. Another trouble is the letter "o". When it is in words such as not, font, moth, bother and broth, it reads [ว ]; but in both, it reads [əu]. When it is in the words nose, hose and rose, it reads [əu]; but in lose, it reads [u:]; and in front, mother and brother, it reads [ $\wedge$ ].

Thirdly, some alphabetical combinations can cause headaches, such as the alphabetical combinations "ea", "or", "ou", "ar" and "ear". When in the words meat, seat, eat, "ea" reads [i:]; but in great and break, it reads [ei]; and in threat and dead, it reads [e]. When in the words work and word, "or" reads [ə:]; but in cork and sward, it reads [o :]. When in the words group and youth, "ou" reads [u:], but in soul, it reads [əu]. When in the words card and cart, "ar" reads [a:]; but in ward and thwart, it reads [0 :]. When in the words ear, fear and beard, "ear" reads [iə]; in the word heard, it reads [ə:]; but in heart, it reads [a:]; and in pear and bear, it reads [eə].

The most outrageous alphabetical combination is "ough" because it has so many pronunciations that we hardly know how to read it! It at least reads eight different ways. When in the words tough and rough, "ough" reads [ $\Lambda \mathrm{f}]$; in the word bough, it reads [au]; in the word cough, it reads [o f]; in the words though and dough, it reads[əu]; in the word hiccough, it reads $[\Lambda \mathrm{p}]$; in the word thorough, it reads [ə]; in the word lough, it reads [o k]; and in the word through, it reads [u:] [2].

Most of the above words are common words. So many words pronounced irregularly or so many illogical phenomena in these common words inevitably constitute obstacles for English learners, especially the beginners.

\section{B. Illogical Language Phenomena Existing in English Word Forms and Meanings}

There are a lot of illogical phenomena existing in English word formation. Here, the illogical phenomena can be divided into two groups: illogical phenomena in word forms and illogical phenomena in word meanings.

\section{1) Illogical Phenomena in Word Forms}

Illogical phenomena in word forms consist of the irregular plural forms of some nouns and the irregular changes of some verbs.

To begin with, let's see the illogical phenomena in the formation of some plural nouns. The plural of duck is ducks; but the plural of goose is geese. The plural of boot is boots; but the plural of foot is feet. The plural of booth is booths; but the plural of tooth is teeth. The plurals of boy and girl are boys and girls; but the plural of child is children. The plurals of box and fox are boxes and foxes; but the plural of ox is oxen. The plural of house is houses; but the plurals of mouse and louse are mice and lice. The plurals of fan and clan are fans and clans; but the plurals of man and woman are men and women.

Besides, we know that, according the rules of pronunciation, the plural of a noun ending with a consonant letter and the letter "o" should add suffix "-es", such as potatoes and tomatoes; but the plurals of the nouns kimono, photo, solo, piano, tobacco and kilo, all add the suffix "-s".

We also know that, the plural of a noun ending with " $\mathrm{f}$ " or "fe" should change the letter "f" or "fe" into "ve", before adding the suffix "-s", such as knife $\rightarrow$ knives and leaf $\rightarrow$ leaves; but the plurals of the nouns roof, proof, gulf, cliff, cuff, grief, belief and safe, all simply add the suffix "-s".

Furthermore, there are a lot of illogical phenomena in the changing of the past forms and past participles of some verbs. For instance, we know the changing of past form and past participle of the verb "bake" is like this: bake $\rightarrow$ baked $\rightarrow$ baked; but take $\rightarrow$ took $\rightarrow$ taken. We know leak $\rightarrow$ leaked $\rightarrow$ leaked; but speak $\rightarrow$ spoke $\rightarrow$ spoken. We know sin $\rightarrow$ sinned $\rightarrow$ sinned; but win $\rightarrow$ won $\rightarrow$ won. We know play $\rightarrow$ played $\rightarrow$ played; but $\quad$ say $\rightarrow$ said $\rightarrow$ said and slay $\rightarrow$ slew $\rightarrow$ slain. We know hit $\rightarrow$ hit $\rightarrow$ hit; but sit $\rightarrow$ sat $\rightarrow$ sat . We know split $\rightarrow$ split $\rightarrow$ split; but spit $\rightarrow$ spat $\rightarrow$ spat. We know think $\rightarrow$ thought $\rightarrow$ thought; but shrink $\rightarrow$ shrank $\rightarrow$ shrunk, etc.

\section{2) Illogical Phenomena in Word Meanings}

Illogical phenomena in word meanings include the illogical meanings of some derivatives, compounds and phrases.

First, there are a lot of illogical phenomena in the meanings of some derivatives. For example, we know that the word inactive is the opposite of the word active; but invaluable is not the opposite of the word valuable. We know that the opposite of the word able is unable; yet the opposite of the word capable is incapable.

Second, the illogical phenomena in the meanings of some compounds are more serious. Generally speaking, we can guess the meaning of a compound from its components, such as moonlight, schoolbag, etc. Nevertheless, there are many compounds where the meanings cannot be guessed from its components — their meanings haven't any logical relations with their components. To name a few: highboy is not a tall boy, it is "a tall piece of wooden furniture containing several drawers" [3]; dog-ear is not the ear of a dog, it is "a corner of a page turned down to mark your place"; sweetmeat does not mean sweet meat, it is "a sweet or any food made of or preserved in sugar" [3]; ladybird is not a bird nor is it female either, it is "a small round beetle that is usually red with black spots" [3]; guinea pig is not a pig at all, and it does not come 
from Guinea, it is "a small roundish furry animal rather like a rabbit but with short ears and no tail, which is often kept by children as a pet, and is sometimes used in scientific tests" [3]; parkway is for driving, not for parking, and driveway is mainly for parking, not for driving; there is no egg in the eggplant and there is no ham in the hamburger. Such words are in large numbers, and cannot be taken literally; otherwise; they may lead to comical situations or even cause trouble.

There are also a large number of illogical phenomena in the meanings of some phrases. For example, sporting house means a building where prostitutes are available, not a house for sports; horse sense means common sense, not the sense of a horse; goose flesh means "a condition in which the skin is raised up in small points because a person is cold or frightened" [3], not the flesh of the goose; morning glory is a climbing plant with blue, white or pink flowers, not the glorious scene in the morning; at the eleventh hour is at the last possible moment, not at eleven o'clock. And blue stocking means a woman scholar; couch potato means a TV fan; white feather means a coward; French letter is a condom; Russia dressing is mayonnaise; Dutch wife is "a long hard bolster, made of materials like rattan, wicker or bamboo, known as Zhufuren" [4], and so on. Such phrases are too numerous to list.

Still, some phrases seem to be opposite in meaning, but in fact they mean the same, such as fill in (a form) and fill out ( $a$ form); burn down and burn up; slow down and slow up; a slim chance and a fat chance, etc. These phenomena really make people feel rather baffled.

\section{Illogical Language Phenomena Existing in English Syntax and Syntactic Meaning}

Illogical Language Phenomena Existing in English syntax and syntactic meaning are countless, as well. Some scholars have discussed this kind of phenomena from several aspects, such as "passive meaning in active form", "active meaning in passive form", "negative meaning in affirmative form", "affirmative meaning in negative form" [5], "indicative mood in subjunctive mood", "specious sentences" and "paradoxical sentences", etc [5]. The following are some typical examples.

\section{1) Passive Meaning in Active Form}

Some English sentences are active in form, but the meanings of the verbs are passive. e.g.

(1) The door won't shut.

(2) The book is worth reading twice.

(3) The story is hard to believe.

(4) Everything looks different to her.

\section{2) Active Meaning in Passive Form}

Some English sentences are passive in form, but the meanings of the verbs are active. e.g.

(1) The boy was lost in the woods.

(2) I am tempted to have another try.

(3) The teacher was satisfied with my answer.

(4) He is advanced in years.

3) Negative Meaning in Affirmative Form

Some English sentences are affirmative in form, but the meanings of the sentences are negative. e.g.

(1) He little knows that the police are about to arrest him.

(2) The patient is too weak to be operated on.

(3) I'm far from blaming him.

(4) His chance of study has gone west.

\section{4) Affirmative Meaning in Negative Form}

Some English sentences are negative in form, but the meanings of the sentences are affirmative. e.g.

(1) It can't be worse.

(2) It was no less a person than Tom.

(3) No sooner did we get on the train than it started .

(4) He doesn't lend his books to nobody.

5) Indicative Mood in Subjunctive Mood

English subjunctive mood is usually used in a complex sentence with an unreal condition to express an unreal situation. But, in fact, the subjunctive mood can express a lot more meanings. e.g.

(1) If only the wind would stop! ( To express a wish)

(2) We suggested that the operation should be started at once. (To express a suggestion)

(3) The general ordered that the horse should be ready. (To express an order)

(4) I don't think he would be so careless. (To express an opinion)

\section{6) Specious Sentences}

Some English sentences apparently seem to mean this, but in fact they mean that. Understanding these kinds of sentences according to the grammar or logic often leads to misunderstanding and even grotesquerie. They are usually slang or idioms, which have special meanings different from their apparent meanings. e.g.

(1) You let me down doing things like that. (Meaning: You make me feel disappointed doing things like that.)

(2) You can say that again. (Meaning: What you said is interesting!)

(3) You are killing me. (Meaning: What you said crack me up.)

(4) You are all wet. (Meaning: You are totally wrong.) mean?)

(5) What are you smoking? (Meaning: What do you

6) She gave him the air. (Meaning: She made a clean break with him.)

\section{7) Paradoxical sentences}

Some English sentences are grammatically and logically wrong, but actually they are right in reality. For example, traditional grammar says the word "less" is the comparative degree of the word "little" and usually modifies the uncountable noun; but some scholar points out that the native speakers of English often use "less" before countable nouns [6]. e.g.

(1) Try to make less mistakes.

(2) Less new cars were bought last year than ever before.

For another example, according to English grammar, when participle phrases or infinitive phrases are used as an adverbial, their implied logical subjects should be consistent 
with the subjects of the main clauses, but some scholar notes that sometimes the implied logical subjects of some participle phrases or infinitive phrases are inconsistent with the subjects of the main clauses, and the sentences hold water [7]. e.g.

(1) Roughly speaking, these countries are the most advanced in the area.

(2) Considering the cost of labour, the price is reasonable.

(3) To call a spade a spade, he can't be depended upon.

(4) To sum up, she is a nice girl.

Furthermore, there is a form of a negative sentence, which is called "transferred negation", i.e. the negative sentence is formed by transferring the negative word from its original place to another place, thus making the sentence seem to be illogical or difficult to understand. This kind of sentences should be read carefully. e.g.

(1) He wasn't late because he was ill. (=He was late not because he was ill.)

(2) I don't pretend to understand these technical terms. (=I admit that I do not understand them. [3])

\section{The Causes and Enlightenments of the English Illogical Phenomena}

\section{A. The Causes of the English Illogical Phenomena}

The existence of English illogical phenomena results from the symbolic nature of languages. A language is a "special symbolic system" combined with sounds and meanings.

We say it is a "symbolic system", because it is a convention established by certain groups of people due to the requirement of social communication in the long-term process of social practice. The popular acceptance of a language is determined by the nature of the language. Since human thoughts reflect objective things and languages express human thoughts, the relations between a language and objective things are indirect. They are not a one-to-one relationship. That means, on the one hand, one language symbol can refer to different objects; on the other hand, one object can be expressed by different language symbols, i.e. one language form can express different thoughts; and one thought can be expressed by different language forms.

The randomness and regularity are the characteristics of the symbolic system. Randomness means the relationship between the symbol content and the symbol form are at random - there is no necessary or entitative link between them. Regularity means the relationship between the symbol content and the symbol form are stipulated—once they are stipulated, everyone should abide by.

The randomness and regularity of the symbolic system are some of the reasons why there are so many illogical phenomena in English language.

When we say that a language is a "special" symbolic system, we mean it is different from an ordinary symbolic system. Ordinary symbolic system could remain fixed for a long period of time; but the symbolic system of a language always changes and develops with the fast changing and developing society [1]. In the long development process of human history, the language of a nation changes constantly under various influences, such as the metabolism of the language itself, the alien invasion, the integration of nations, the communication of different cultures, etc.

English is just the case_-it changes and develops with the constantly changing and developing society, meanwhile, it takes on numerous foreign language components, thus causing all kinds of "illogical language phenomena" in every aspect of English. All English grammar books are limited, and they can not reveal all the language phenomena which are constantly changing. Languages in reality always inevitably overstep the grammar rules or are inconsistent with grammar rules. It is these illogical phenomena in English that cause the richness, complexity, variety and flexibility of English language, making English more vigorous and vital.

\section{B. The Enlightenments of the English Illogical Phenomena}

The great Hungarian master of language, K. Lomb once said that the language whose rule effectiveness is limited, is the difficult one to learn [8]. English is such a language. Although it is alphabetic writing, its phonics rules can not cover all the cases, there are non-spelling elements in it; there are so many irregular or illogical phenomena in word formation and meaning, we have to call them illogical words; and there are so many illogical phenomena in the sentence patterns and their syntactic meanings, we have to call them "special expressions" or "idiomatic expressions". All these illogical phenomena may rouse English learners' curiosity and interest, leading them to do further study of the roots or causes; but they may also become obstacles and difficulties for English learners. In order to learn English well and to gain a higher English level, we must put in extra effort and pay more attention to them, and based on the general rules and regulations of a language, get sufficient understanding and mastering of these illogical phenomena.

\section{References}

[1] Zhenkun Wang, Wenqing Xie, and Zhenduo liu, Linguistic Foundation, Beijing: Central Radio \& TV University Press, 1983, pp. 40-44, 45-52.

[2] T.S. Watt. "English".[D/OL]. https://schoolspirit.edublogs.org/2008/04/28/english-a-poem-by-ts-watt/

[3] D. Summers, Longman Dictionary of English Language \& Culture, Beijing: The Commercial Press, 2004, pp.1797,1782,971,750,775, 1379.

[4] Wikipedia the Free Encyclopedia. [D/OL] http://en.wikipedia.org/wiki/Dutch_wife

[5] Xuegong Liu, Yongke Liu, Contradictions in English Expressions, Beijing: China International Radio Press, 1992, pp.1-68, 145-163.

[6] Xiaoli Zhu,"Tentative study on contradictory phenomena in English grammar teaching," Science, no.4, pp.113-114, February 2008.

[7] Jianying Miao, "Research on illogical English expressions," Journal of Sichuan Vocational and Technical College, no.3, pp.93-95, August 2003.

[8] K. Lomb, How I Study Foreign Language-Learning Sixteen Languages in Twenty-five Years, Beijing: Foreign Language Teaching and Research Press, 1982. 